\title{
A trial of chemoprophylaxis of natural influenza infection with U.K. 2371
}

\author{
J. E. S T A R K, R. B. HE A T H, N. C. O S W A L D \\ St. Bartholomew's Hospital, London
}

VIVIEN BOOTH, RUTH TALL, W A L L A CE F O X
M.R.C. Tuberculosis and Chest Diseases Unit, Brompton Hospital, London

K. D. MOYNAGH

Medical Officer, The City University, London

J. M. INGLIS

Virus Laboratory, Brompton Hospital, London

\begin{abstract}
In a five-week double-blind trial, 132 young adult volunteers received U.K. 2371, a synthetic isoquinoline derivative which had previously been shown to protect volunteers against challenge with certain influenza viruses. A comparable group of 130 volunteers received placebo. There was little difference between the groups in number or severity of acute respiratory illnesses during the trial or in the number of proven infections with influenza A2/Hong Kong/1968 virus. Tablet counts were carried out and single doses of isoniazid were used as a marker to confirm that the lack of prophylaxis was not the result of the failure of volunteers to ingest the tablets.

It is possible that the disparity between our results and those obtained in previous volunteer challenge studies may be due to differences in susceptibility of strains of influenza A virus to the isoquinoline drugs.
\end{abstract}

Certain synthetic isoquinoline derivatives have been shown to inactivate influenza $A$ and $B$ and parainfluenza viruses in vitro and to protect some laboratory animals against challenge with these viruses (Larin, Beare, Copping, McDonald, McDougall, Roberts, and Smith, 1968 ; Coombes, Brammer, Herbst-Laier, Larin, McDonald, Tute, Wickham, and Williamson, 1969).

Beare, Bynoe, and Tyrrell (1968) reported that the oral administration of one of these drugs (U.K. 2371) to volunteers reduced by half the incidence of virus infection and of clinical illness after intranasal instillation of living influenza B virus. There seemed also to be a reduction in the rate of infection of a small number of volunteers who were challenged with a 1965 strain of influenza A2 virus, but subsequent experiments failed to show protection of volunteers challenged with influenza A2/Hong Kong/1968 (Reed, Beare, Bynoe, and Tyrrell, 1970).

The present study was carried out to assess the effectiveness of a five-week course of oral U.K. 2371 in prophylaxis against natural infection with influenza A2/Hong Kong/1968. The trial was planned by a group containing clinicians, virologists, statisticians, biochemists, and haematologists.

\section{METHODS}

The trial took place in January and February 1969 in a university hall of residence which accommodates 390 male students of engineering and optics. After discussions with the hall authorities and with representatives of the students, a written account of the plan of the trial was sent to the students in November 1968. They were asked to discuss this with their parents during the Christmas vacation and those under 21 years of age were informed of the need for signed parental consent. Students who volunteered were enrolled, on return from vacation, between 5 and 11 January 1969. All students were considered eligible unless they had been immunized against influenza A2/Hong Kong/1968, had known or suspected liver or blood disease or were receiving other drugs which might complicate assessment.

Volunteers were seen by one of us (J.E.S.) at their enrolment and were questioned about respiratory symptoms during the previous month and about 
current symptoms. Those with symptoms were examined clinically. The plan and procedures of the trial were again explained to each volunteer individually. Twenty millilitres of venous blood was then collected from each volunteer. All volunteers were seen again as a routine at two weeks and at five weeks, the end of the trial. On each occasion they were questioned about respiratory and non-respiratory symptoms and were asked for another blood sample.

In addition the volunteers were asked to report in person all symptoms occurring during the trial and a doctor was always available for this purpose. Nearly all volunteers who reported symptoms were seen by one of us (J.E.S.), who recorded symptoms and signs on a standard form and took throat swabs from those with respiratory symptoms. Volunteers who reported symptoms were asked to attend daily until their symptoms had gone. Further, a short questionnaire was delivered to all volunteers once a week, requesting information about any symptoms which had occurred during the preceding week. Finally, a questionnaire was sent to all volunteers one month after the end of the trial requesting information about symptoms which had developed since stopping the tablets.

Film-coated tablets containing $250 \mathrm{mg}$. of U.K. 2371 and placebo tablets of identical size and appearance (containing trace amounts of extract of quassia to simulate the bitter taste of the isoquinoline) were individually packaged in metal foil. Eight tablets for each day were mounted on a card in four pairs, and the pairs were clearly marked 'breakfast', 'lunch', 'supper', and 'bedtime'. The daily dose of U.K. 2371 was $1.5 \mathrm{~g}$. (six tablets), issued as two tablets to be taken at breakfast and at supper, and one tablet to be taken at lunch and at bedtime. Placebo tablets were added to the U.K. 2371 cards to complete the pairs at lunch and bedtime, so that all doses consisted of two tablets and so that a marker tablet could be substituted for one of the two placebo tablets. The placebo cards contained four pairs of placebo tablets. A marker tablet containing $150 \mathrm{mg}$. of isoniazid and indistinguishable from the U.K. 2371 and placebo tablets was substituted for a bedtime placebo tablet on one day a week, chosen at random, in both U.K. 2371 and placebo regimens.

Sets of 35 U.K. 2371 or placebo cards with the marker tablets added were prepared in advance for each volunteer for the whole trial and were serially numbered. At enrolment volunteers were randomly allocated one of the pre-prepared sets; the cards were then labelled with the student's name and room number. The trial was double-blind, neither the volunteers nor the medical and nursing staff being aware of the regimen allocated to any volunteer. One card from his set was delivered to the room of each volunteer before 7.00 every morning for the 35 days of the trial. Volunteers were instructed to remove and swallow the tablets at the times indicated and to return the cards on the day after issue by dropping them into one of a number of boxes which had been placed in the hall of residence for that purpose. They were asked to leave on the cards all tablets which, for any reason, had not been swallowed. A record was kept of the cards returned and reminders were sent if cards were not returned at the correct time. Early in the morning of the day after a marker tablet had been issued a letter requesting a specimen of urine was delivered to the volunteer together with a small container for the specimen. It was requested that the specimen should, if possible, be the first passed that morning.

\section{CLASSIFICATION OF SYMPTOMS}

The forms on which details of symptoms and of physical examination had been recorded were studied at the end of the trial by one of us (N.C. O.) and episodes were classified according to the following criteria without knowledge of the results of laboratory tests or of the regimen allocated to the volunteer :

Cold Nasal discharge and excessive use of handkerchiefs

Sore throat Pain or soreness of the throat as the initial symptom of the episode, but with no nasal discharge or excessive use of handkerchiefs

Influenza-like illness Respiratory symptoms in association with either headache, muscle aches or shivering and severe enough to cause the volunteer to miss time from his studies

Non-respiratory illness Symptoms which were not related to the respiratory tract.

Colds and sore throats were graded as 'severe' if volunteers missed studies or worked only part-time and 'mild' if normal studies were continued.

The weekly questionnaires reporting additional symptoms were also classified according to the criteria described above.

\section{LABORATORY INVESTIGATIONS}

ISOLATION OF VIRUSES AND Mycoplasma pneumoniae A throat swab was taken from all volunteers at enrolment for attempted isolation of Mycoplasma pneumoniae and further throat swabs for virus and mycoplasma isolations were taken when subjects attended with respiratory illnesses.

Virus isolation was carried out in secondary monkey kidney tissue cultures. Cultures were examined for cytopathic changes and were tested for haemadsorption after 5 and 10 days' incubation in roller drums at $36^{\circ} \mathrm{C}$. Isolates were identified in haemagglutinationinhibition tests with standard sera.

Mycoplasma isolations were attempted in selective diphasic medium (Chanock, Fox, James, Gutekunst, White, and Senterfit, 1967).

SEROLOGY Sera collected at enrolment and at 2 and 5 weeks were stored at $-20^{\circ}$ C. and titrated for virus and mycoplasma antibodies at the end of the trial. 
Antibodies against influenza A2/Hong Kong/1968, influenza $B /$ England/1966, and parainfluenza viruses 1,2 and 3 were estimated by the haemagglutinationinhibition (H.I.) technique previously described (Heath, Tyrrell, and Peto, 1962).

Antibodies against influenza $A$, influenza $B$, adenoviruses, respiratory syncytial virus and $M y c o-$ plasma pneumoniae were estimated by the complement fixation technique of Bradstreet and Taylor (1962).

HAEMATOLOGY A thin blood film was prepared at the time of collection. The haemoglobin level, packed cell volume and total and differential white blood counts were estimated on all blood samples. The number of platelets was assessed from the stained fi.m and a count was carried out only when a low count was suspected.

BIOCHEMISTRY Serum total bilirubin, alkaline phosphatase and serum aspartate aminotransferase (SGOT) were estimated on all blood samples. Standard AutoAnalyzer techniques were used. Bilirubin was estimated by the method of Gambino and Schreiber (1964). Blank determinations were carried out on all samples giving a total serum bilirubin of over $0.5 \mathrm{mg} . / 100 \mathrm{ml}$. Serum alkaline phosphatase was estimated by a modification of the method of Powell and Smith (1954) and SGOT by the method of Morgenstern, Oklander, Auerbach, Kaufman, and Klein (1966).

The results of haematological and biochemical tests were scrutinized within 48 hours of collection of blood so that abnormal findings could be confirmed by further blood tests and so that tablets could be stopped if toxicity was suspected.

URINE TESTS FOR ACETYL-ISONIAZID Urine specimens were stored at $4^{\circ} \mathrm{C}$. until the end of the trial and were then tested for acetyl-isoniazid by the method of Eidus and Hamilton (1964).

\section{RESULTS}

Two hundred and sixty-five male students volunteered for the trial, of whom two were considered unsuitable, one because of recent immunization with a vaccine containing influenza $\mathrm{A} 2 /$ Hong Kong/1968 and the other because of concurrent treatment with an antidepressive drug. One volunteer enrolled but was excluded before taking any tablets when he was discovered to have glandular fever. There remained 262 eligible volunteers, of whom 132 were allocated to the U.K. 2371 regimen and 130 to placebo.

Eight volunteers (6 U.K. 2371 and 2 placebo) failed to complete the trial. Data on these volunteers have been included in the analysis up to the time they left the trial. Of the U.K. 2371 volunteers, one withdrew because of admission to hospital for an unrelated condition, one returned home for treatment of depression, one was advised by a doctor to stop all drugs after an episode of otitis media, one left the hall to live elsewhere, and two asked to be withdrawn because of pressure of work. All denied side-effects from the tablets. Of the volunteers in the placebo group one left the hall to live elsewhere and the other failed to continue after two weeks because of loss of interest in the trial.

COMPARISONS ON ADMISSION The age distributions of the volunteers in the drug and placebo groups were broadly similar (Table I), nearly all subjects being between the ages of 18 and 23 years.

Sixty-seven $(52 \%)$ of the 132 volunteers in the U.K. 2371 group and $78(60 \%)$ of 130 in the placebo group had had a respiratory illness during

T A B L E I

AGE DISTRIBUTION OF VOLUNTEERS

\begin{tabular}{|c|c|c|c|c|c|c|c|c|}
\hline \multirow{2}{*}{\multicolumn{3}{|c|}{ Group }} & \multirow{3}{*}{\begin{tabular}{|c|} 
Total Volunteers \\
132 \\
130
\end{tabular}} & \multicolumn{5}{|c|}{ Age (yr) } \\
\hline & & & & \multirow{2}{*}{\begin{tabular}{cr}
\multicolumn{2}{|c|}{$\begin{array}{l}\text { 18 and } \\
\text { No. }\end{array}$} \\
37 \\
41 & 28 \\
\end{tabular}} & \multirow{2}{*}{\begin{tabular}{cr}
\multicolumn{2}{c}{20 and 21} \\
No. & $\%$ \\
72 & 55 \\
60 & 46
\end{tabular}} & \multirow{2}{*}{\begin{tabular}{cc}
\multicolumn{2}{c}{22 and 23} \\
No. & $\%$ \\
18 & 14 \\
16 & 12 \\
\end{tabular}} & \multirow{2}{*}{$\begin{array}{rr}24 \text { or over } \\
\text { No. }\end{array}$} & \multirow{2}{*}{\begin{tabular}{cc}
\multicolumn{3}{|c}{ Not known } \\
No. & $\%$ \\
2 & 1 \\
0 & 0
\end{tabular}} \\
\hline $\begin{array}{l}\text { U.K. } 2371 \\
\text { Placebo }\end{array}$ & & $\begin{array}{l}\cdots \\
\cdots\end{array}$ & & & & & & \\
\hline
\end{tabular}

T A B L E I I

PRETREATMENT LEVELS OF HAEMAGGLUTINATION-INHIBITION ANTIBODY

\begin{tabular}{|c|c|c|c|c|c|c|c|}
\hline \multirow{2}{*}{\multicolumn{3}{|c|}{ Group }} & \multirow[b]{2}{*}{ Total Volunteers } & \multicolumn{4}{|c|}{ Reciprocal of Haemagglutination-inhibition Antibody Titre } \\
\hline & & & & $\begin{array}{l}8 \text { or less } \\
\text { No. } \%\end{array}$ & $\begin{array}{l}16 \text { or } 32 \\
\text { No. } \%\end{array}$ & $\begin{array}{l}64 \text { or more } \\
\text { No. } \%\end{array}$ & $\begin{array}{l}\text { Not Available } \\
\text { No. } \%\end{array}$ \\
\hline $\begin{array}{l}\text { U.K. } 2371 \\
\text { Placebo }\end{array}$ & $\ddot{*}$ & . & $\begin{array}{l}132 \\
130\end{array}$ & $\begin{array}{l}95 \\
92\end{array}$ & $\begin{array}{l}19 \\
26\end{array}$ & $\begin{array}{l}5 \\
2\end{array}$ & $\begin{array}{l}5 \\
1\end{array}$ \\
\hline
\end{tabular}


the month before the trial. One volunteer in the U.K. 2371 group and three in the placebo group described this illness as 'influenza'.

The pretreatment titres of H.I. antibody against influenza A2/Hong Kong/1968 are shown in Table II. A high proportion of volunteers in each group had initial antibody levels of 8 or less and only a small number in each group had initial titres of 64 or greater. It may be concluded that the pre-trial titres of H.I. antibody against influenza A2/Hong Kong/1968 were similar in the drug and placebo groups.

RESPIRATORY EPISODES (Table III) During the five weeks of the trial $57(43 \%)$ of the volunteers in the U.K. 2371 group reported 65 respiratory episodes compared with 55 respiratory episodes reported by $50(39 \%)$ of the volunteers in the placebo group.

The clinical classification of these episodes is shown in Table IV. There were nine episodes of influenza-like illness in the U.K. 2371 group and six in the placebo group. The numbers of sore throats and colds in the two groups were very similar.

The laboratory confirmation of virus infections is shown in Table V. Infection with influenza A2/Hong Kong/1968 was detected by a rise of H.I. antibody in 12 volunteers, 4 of whom also developed a rise of complement-fixation antibody. Nine of the 12 confirmed influenza A2 infections occurred in volunteers receiving U.K. 2371 and 3 in those receiving placebo. Ten of the 12 who developed a diagnostic rise of antibody had a pretreatment H.I. antibody titre of less than 8 , one had an initial titre of 8 and one volunteer in the U.K. 2371 group had a pre-trial titre of 128 which suggests that he was infected before the start of the trial.

The classification of the illnesses associated with influenza A2/Hong Kong/1968 infections is shown in Table IV. Of the nine volunteers in the U.K. 2371 group who had laboratory evidence of infection, four had an influenza-like illness, one had a mild sore throat, two had mild colds and two reported no symptoms. Two of the volunteers in the placebo group who had laboratoryconfirmed influenza A2 infection suffered influenzalike illnesses and the other had a mild sore throat. There was, therefore, no apparent difference in the severity of the illnesses associated with influenza A2 infection in the drug and placebo groups.

Parainfluenza 1 virus was recovered from three volunteers, two of whom were receiving U.K. 2371 (Table V). All three were suffering from an influenza-like illness at the time the throat swab was taken. Herpes simplex virus was recovered from a volunteer with severe stomatitis in the U.K. 2371 group. There was no laboratory evidence of infection with influenza $B$ virus, parainfluenza 2 or 3 viruses, respiratory syncytial virus, adenovirus, or Mycoplasma pneumoniae.

NON-RESPIRATORY EPISODES Of the 132 volunteers who received U.K. 2371, $53(40 \%)$ reported 60 non-respiratory episodes (Table III) compared

T A B L E I I I

RESPIRATORY AND NON-RESPIRATORY EPISODES DURING THE TRIAL

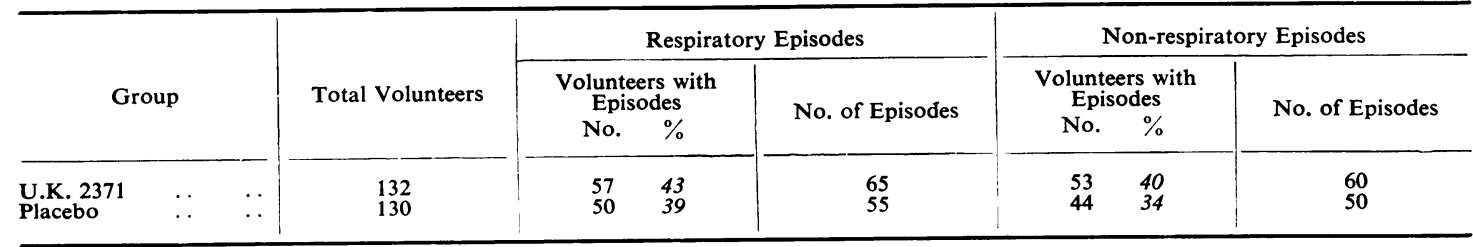

T A B L E I V

RESPIRATORY EPISODES

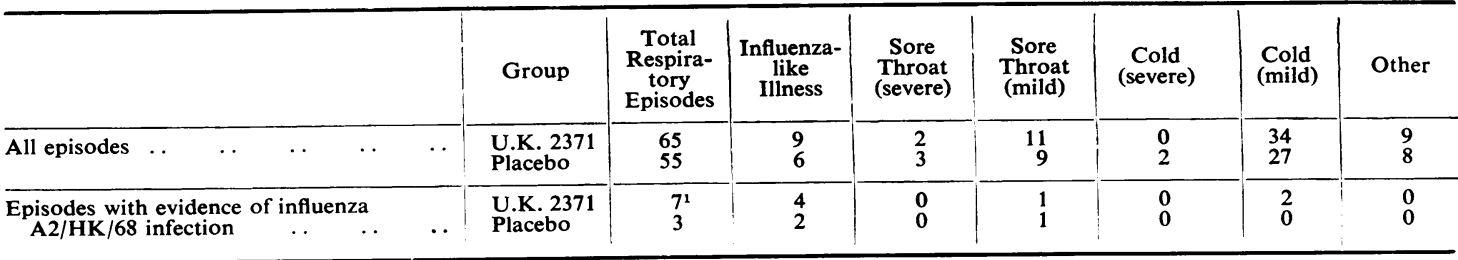

1 In addition there were two subjects who reported no symptoms but who had serological evidence of infection. 
T A B L E V

LABORATORY CONFIRMATION OF DIAGNOSIS

\begin{tabular}{|c|c|c|c|c|c|c|}
\hline \multirow{2}{*}{ Virus } & & \multirow{2}{*}{ Group } & \multicolumn{2}{|c|}{ Volunteers with Antibody Rise } & \multirow{2}{*}{$\begin{array}{l}\text { No. of } \\
\text { Isolations }\end{array}$} & \multirow{2}{*}{$\begin{array}{l}\text { Total Diagnoses } \\
\text { (antibody rise } \\
\text { and/or isolation) }\end{array}$} \\
\hline & & & $\begin{array}{l}\text { Haemagglutination } \\
\text { Inhibition }\end{array}$ & $\begin{array}{l}\text { Complement } \\
\text { Fixation }\end{array}$ & & \\
\hline Influenza A2/HK/68 & $\cdots$ & $\begin{array}{l}\text { U.K. } 2371 \\
\text { Placebo }\end{array}$ & $\begin{array}{l}9 \\
3\end{array}$ & $\begin{array}{l}3 \\
1\end{array}$ & $\begin{array}{l}\mathbf{0} \\
\mathbf{0}\end{array}$ & $\begin{array}{l}9 \\
3\end{array}$ \\
\hline Parainfluenza $1 \quad \ldots$ & $\cdots$ & $\begin{array}{l}\text { U.K. } 2371 \\
\text { Placebo }\end{array}$ & $\begin{array}{l}1 \\
0\end{array}$ & $\begin{array}{l}\mathbf{0} \\
\mathbf{0}\end{array}$ & $\begin{array}{l}2 \\
1\end{array}$ & $\begin{array}{l}2 \\
1\end{array}$ \\
\hline
\end{tabular}

T A B LE VI

NON-RESPIRATORY SYMPTOMS

\begin{tabular}{|c|c|c|c|c|c|}
\hline \multirow{2}{*}{\multicolumn{4}{|c|}{ Symptom }} & \multicolumn{2}{|c|}{$\begin{array}{c}\text { No. of Times } \\
\text { Symptom Reported }\end{array}$} \\
\hline & & & & $\underset{\text { Group }}{\text { U.K. } 2371}$ & $\begin{array}{l}\text { Placebo } \\
\text { Group }\end{array}$ \\
\hline 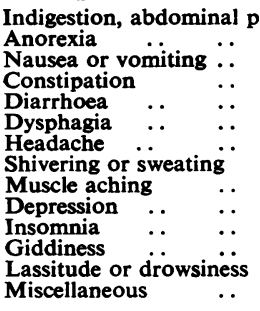 & $\begin{array}{l}\text { no } \\
\therefore \\
\cdots \\
\cdots \\
\cdots \\
\cdots \\
\cdots \\
\cdots \\
\cdots \\
\cdots\end{array}$ & $\begin{array}{l}\text { atul } \\
\cdots \\
\cdots \\
\cdots \\
\cdots \\
\cdots \\
\cdots \\
\cdots \\
\cdots \\
\cdots \\
\cdots\end{array}$ & $\begin{array}{l}\text { e } \\
\cdots \\
\cdots \\
\cdots \\
\cdots \\
\cdots \\
\cdots \\
\cdots \\
\cdots \\
\cdots \\
\cdots\end{array}$ & $\begin{array}{r}9 \\
1 \\
7 \\
2 \\
4 \\
4 \\
9 \\
6 \\
3 \\
5 \\
3 \\
7 \\
13 \\
5\end{array}$ & $\begin{array}{r}7 \\
1 \\
3 \\
1 \\
4 \\
1 \\
15 \\
1 \\
1 \\
6 \\
5 \\
4 \\
14 \\
5\end{array}$ \\
\hline
\end{tabular}

with 50 non-respiratory episodes reported by 44 (34\%) of the volunteers in the placebo group.

Individual non-respiratory symptoms are listed in Table VI. There were no important differences between the groups. Most of the episodes were slight and in no case was it necessary for a doctor to interrupt the medication for more than 24 hours because of suspected side-effects. The most troublesome non-respiratory symptom was low substernal pain on swallowing food, which occurred in four volunteers who were taking U.K. 2371 and in one who was receiving placebo. A similar symptom developed during the trial in one other student who lived in the hall but was not participating in the trial. The dysphagia lasted up to three days and improved in spite of the continued administration of tablets.

TOXICITY Results of the SGOT, alkaline phosphatase, bilirubin, packed cell volume and white cell counts were obtained for the volunteers before treatment, and at two weeks and five weeks after the start of the study. The differences between the U.K. 2371 and the placebo groups were small and did not suggest changes due to drug toxicity.

CO-OPERATION OF VOLUNTEERS TAKING MEDICAMENTS Information obtained from tablet counts and from tests for acetyl-isoniazid in the urine will be reported in full elsewhere (Stark et al., in preparation).

In brief, $94.8 \%$ of 36,368 tablets issued to volunteers in the U.K. 2371 group and $94.9 \%$ of 36,248 issued to the placebo group were removed by the volunteers from the cards on which they were mounted. One hundred and eleven $(84 \%)$ of 132 volunteers in the U.K. 2371 group and $107(82 \%)$ of the 130 in the placebo group removed more than $90 \%$ of their tablets from the cards, and only $6(5 \%)$ volunteers in the U.K. 2371 group and $4(3 \%)$ in the placebo group removed fewer than $80 \%$ of their tablets.

A positive test for acetyl-isoniazid was obtained in $962(90 \%)$ of the 1,062 urine specimens received when a marker tablet was known to have been removed from the previous day's card, indicating a high rate of ingestion of the tablets. Further analyses, which will be reported elsewhere, did not demonstrate an association either between failure to remove U.K. 2371 tablets from the cards or between negative urine results and the incidence of respiratory illnesses during the trial. Thus, there was no evidence that the absence of an antiviral effect in this trial was the result of a failure of the volunteers to take their U.K. 2371 tablets.

\section{DISCUSSION}

U.K. 2371 administered orally had no effect on the number of acute respiratory illnesses experienced by young adult volunteers during the five weeks of this trial. Although there was no major outbreak of influenza in London during the winter of 1968/69, influenza A2/Hong Kong/1968 was the predominant myxovirus causing infection during the trial. Although the total number of laboratory-confirmed infections was very small, the finding that 9 of the 12 influenza A2 infections and 2 of the 3 parainfluenza infections occurred in volunteers receiving U.K. 2371 suggests that there was little if any antiviral effect under the conditions of this trial. 
Beare et al. (1968) had reported previously that a small number of volunteers receiving U.K. 2371 acquired a degree of protection against challenge with a strain of influenza $B$ virus (influenza B/England/101/62) which had been shown to be sensitive to the drug in vitro. The results with a strain of influenza A2 virus (A2/Leningrad/4/65) in another small study were less conclusive. In vitro tests of the susceptibility of different strains of influenza A and B viruses to U.K. 2371 have given variable results depending upon the techniques used. Larin et al. (1968), using an egg inoculation method, found that several influenza B strains were more susceptible than influenza A2/Singapore/57, and Coombes et al. (1969) showed that influenza/A2/Hong Kong/1968 was less susceptible than influenza A2/Singapore/57 in the same system. On the other hand, Reed et al. (1970), using a tissue culture method, were unable to demonstrate differences in susceptibility between strains of influenza A2 and B viruses (including the B strain used in the challenge experiments of Beare et al. (1968) ) and the A2/Hong Kong/1968 strain used in their challenge experiments. The same workers showed that, although U.K. 2371 was active against parainfluenza 2 virus in tissue culture systems, there was no demonstrable activity against this virus in human challenge experiments. There seems, therefore, to be no consistent relationship between the susceptibility of virus strains to U.K. 2371 in vitro and the degree of protection obtained in human challenge studies. There is insufficient information to relate the results of challenge experiments to protection against natural virus infection, but, at present, clinical trial against natural infection is usually considered to be justified only if protection has been demonstrated in challenge experiments.

The frequency with which patients fail to take their medicaments has been demonstrated on many occasions (Fox, 1962 ; Porter, 1969) and it might be expected that the omission of tablets would be even more frequent when healthy volunteers were receiving prophylaxis against a disease such as influenza. Supervision of administration of tablets is rarely feasible in large prophylactic trials, particularly when volunteers are studied in their home or working environment and when several daily doses are required. An absence of therapeutic or prophylactic effect in such trials may erroneously be ascribed to ineffectiveness of the drug when it is in fact due to failure of volunteers to ingest their medicaments. For these reasons, two methods of assessing the acceptance of tablets were incorporated into this trial. Tablets were issued daily and those returned on tablet cards were counted. The fact that over $94 \%$ of the tablets issued to each group were removed from the cards was gratifying but did not indicate that the tablets were necessarily being swallowed. The presence of acetyl-isoniazid in the urine of subjects who had removed a marker tablet containing isoniazid from the card on the previous day was good evidence of ingestion of that tablet. The marker tablets were indistinguishable from the other tablets, their presence was unknown to the volunteers, and so we think that the number of positive urine tests is a good index of the number of drug and placebo tablets ingested. We infer from this method that about $90 \%$ of the drug and placebo tablets were ingested, and thereby discount the possibility that our inability to show an antiviral effect was the result of failure of the volunteers to take the tablets issued to them. Volunteers who failed to ingest tablets fell equally into the two groups: we think this means that failure to take tablets was not a response to unreported side-effects, and hence that the absence of toxicity was not due to failure to take the drug. Finally, it was possible to show that volunteers in the U.K. 2371 group who persistently failed to ingest their tablets did not suffer a disproportionate number of respiratory infections. In the present study a marker substance was required on a few occasions for each subject. In these circumstances isoniazid is very suitable because of its lack of toxicity and because comparatively simple and sensitive tests for its metabolites in the urine are available. In view of its value as an antituberculosis drug it is desirable, however, to restrict its use, as in the present study, to a few occasions only.

We are grateful to the warden and students of Northampton Hall, The City University, for their co-operation, and to Miss A. M. Blanco and Miss R. Everington for valuable nursing assistance.

Haematological and biochemical tests were carried out in the Departments of Haematology and Chemical Pathology, St. Bartholomew's Hospital, and urinary acetyl-isoniazid tests were performed by Miss P. Gammon of the Medical Research Council Unit for Research on Drug Sensitivity in Tuberculosis, Royal Postgraduate Medical School.

U.K. 2371, placebo and isoniazid tablets were provided by Pfizer Ltd.

\section{REFERENCES}

Beare, A. S., Bynoe, M. L., and Tyrrell, D. A. J. (1968). Prophylaxis of influenza with a synthetic isoquinoline. Lancet, $1,843$.

Bradstreet, C. M. P., and Taylor, C. D. E. (1962). Technique of complement-fixation test applicable to the diagnosis of virus diseases. Mth. Bull. Minist. Hlth Lab. Serv., 21, 96. 
Chanock, R. M., Fox, H. H., James, W. D., Gutekunst, R. R., White, R. J., and Senterfit, L. B. (1967). Epidemiology of M. pneumoniae infection in military recruits. Ann. N.Y. Acad. Sci., 143, 484.

Coombes, J. D., Brammer, K. W., Herbst-Laier, R., Larin, N. M., McDonald, C. R., Tute, M. S., Wickham, E. A., and Williamson, G. M. (1969). Laboratory studies on two synthetic dihydroisoquinolines. Paper presented at New York Academy of Sciences quinolines. Paper presented at New York Academy of Scie

Eidus, L., and Hamilton, E. J. (1964). A new method for the determination of $\mathrm{N}$-acetyl isoniazid in urine of ambulatory patients. Amer. Rev. resp. Dis., 89, 587.

Fox, W. (1962). Self-administration of medicaments: a review of published work and a study of the problems. Bull. int. Un. Tuberc., 32, 307.

Gambino, S. R., and Schreiber, H. (1964). The measurement and fractionation of bilirubin on the autoanalyser by the method of

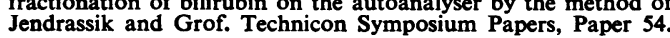

Heath, R. B., Tyrrell, D. A. J., and Peto, S. (1962). Serological studies with Sendai virus. Brit. J. exp. Path., 43, 444.
Larin, N. M., Beare, A. S., Copping, M. P., McDonald, C. R., McDougall, J. K., Roberts, B., and Smith, J. B. (1968). Spectrum and characteristics of the virus-inhibitory action of two isoquinoline derivatives. Antimicrobial Agents and Chemotherapy1967, p. 646.

Morgenstern, S., Oklander, M., Auerbach, J., Kaufman, J., and Klein, B. (1966). Automated determination of serum glutamic oxaloacetic transaminase. Clin. Chem., 12, 95.

Porter, A. M. W. (1969). Drug defaulting in a general practice. Brit. med. J., 1, 218.

Powell, M. E. A., and Smith, M. J. H. (1954). The determination of serum acid and alkaline phosphatase activity with 4-aminoantipyrine (A.A.P.). J. clin. Path., 7, 245.

Reed, S. E., Beare, A. S., Bynoe, M. L., and Tyrrell, D. A. J. (1970). Studies of isoquinoline derivatives (U.K. 2371 and U.K. 2054) in respiratory infections of volunteers, using influenza viruses, a parainfluenza virus and a rhinovirus. Ann. N.Y. Acad. Sci., in press. 